\title{
Arrhythmogenic potential of diuretic induced hypokalaemia in patients with mild hypertension and ischaemic heart disease
}

\author{
DONALD E STEWART, HAMID IKRAM, ERIC A ESPINER, M GARY NICHOLLS
}

From the Departments of Cardiology and Endocrinology, the Princess Margaret Hospital, Christcharch, New Zealand

SUMMARY In view of evidence suggesting an association of mild hypokalaemia with cardiac arrhythmia, the arrhythmogenic potentials of potassium losing and potassium sparing diuretic treatments were compared in a controlled prospective crossover study of 10 patients with mild hypertension and ischaemic heart disease. Mean (SEM) plasma potassium was $4 \cdot 3(0.06) \mathrm{mmol} / \mathrm{l}$ and $3.3(0.07) \mathrm{mmol} / \mathrm{l}$ after potassium sparing and potassium losing treatments respectively. Blood pressure and volume depletion as assessed by weight change, plasma renin activity, and noradrenaline concentrations did not differ significantly in the two treatment periods. The potassium losing treatment phase was associated with an increased frequency of ventricular extrasystoles, a higher Lown grading during ambulatory electrocardiographic monitoring, prolonged duration and decreased phase 0 velocity of the monophasic action potential, a prolonged ventricular effective refractory period, and increased myocardial electrical instability as assessed by programmed ventricular stimulation.

It is concluded that minor changes in plasma potassium concentration are associated with increased ventricular electrical instability in patients with ischaemic heart disease. Mild hypokalaemia in such patients may predispose to life threatening arrhythmias and should be avoided.

Severe hypokalaemia (plasma potassium $<3.0 \mathrm{mmol} / \mathrm{l}$ ) is known to be associated with an increased incidence of cardiac arrhythmias. ${ }^{1-4}$ This risk is further enhanced by the coexistence of myocardial ischaemia, cardiac failure, and digitalis treatment. ${ }^{5-7}$ There have been several reports implicating hypokalaemia of this magnitude as a primary cause of sudden cardiac arrest. ${ }^{8-10}$ The clinical importance of less severe hypokalaemia associated with diuretic treatment (plasma potassium 3.0-3.5 mmol/1), however, remains controversial. Some authorities maintain that any degree of hypokalaemia should be avoided, ${ }^{11}$ whereas others state that only severe hypokalaemia warrants treatment. ${ }^{12-14}$ The controversy has been highlighted recently by the Multiple Risk Factor Intervention Trial ${ }^{15}$ and the re-analysis of the Oslo Study, ${ }^{16}$ both of which showed a greater incidence of sudden death in a

Requests for reprints to Dr Hamid Ikram, Department of Cardiology, The Princess Margaret Hospital, Christchurch 2, New Zealand.

Accepted for publication 14 May 1985 subgroup of diuretic treated hypertensive patients with minor electrocardiographic changes than in patients who were not taking diuretics. The implication of this finding was that diuretic treatment may have increased the risk of fatal cardiac arrhythmias, presumably through potassium or magnesium deficiency. Such a possibility must remain speculative until it can be shown in prospective controlled studies that cardiac electrical instability is consistently associated with mild hypokalaemia.

We investigated cardiac electrical instability in $N$ patients with mild hypertension and known coronary $N$ artery disease during treatment with a potassium los- $N$ ing diuretic and again after a similar period of treatment on a potassium sparing diuretic. We assessed myocardial electrical instability by several techniques and used an intrapatient crossover design to provide $\stackrel{\oplus}{\Phi}$ controlled data. Because of a possible role of increased sympathetic activity during volume depletion, changes in plasma catecholamine concentrations, as $\mathbb{D}$ well as renin/angiotensin/aldosterone activity, were also studied. 


\section{Patients and methods}

The protocol was approved by the ethical committee of the Canterbury Hospital Board and all patients signed a consent form after a full explanation of the procedures. Eleven patients were recruited from the outpatient department. Their clinical details are given in Table 1. We used the following inclusion criteria: (a) the presence of mild hypertension (supine diastolic pressure phase $5,90-100 \mathrm{~mm} \mathrm{Hg}$ ) measured on two consecutive outpatient visits; $(b)$ a clinical history of typical effort angina; and $(c)$ absence of clinically manifest atrial arrhythmias. Patients with impaired renal function, potassium abnormalities before the start of the study, known hypersensitivity to thiazides or amiloride, and those who were pregnant were excluded.

\section{STUDY DESIGN}

The study followed a randomised crossover design and consisted of eight weeks' treatment with a potassium sparing diuretic and eight weeks' treatment with a potassium losing compound. Nine patients received amiloride $10 \mathrm{mg}$ twice daily as the potassium sparing diuretic. One patient received spironolactone (Aldactone A) $25 \mathrm{mg}$ twice daily because of nausea attributed to amiloride. Eight patients received chlorthalidone $25 \mathrm{mg}$ twice daily as the potassium losing drug. Two patients with chlorthalidone intolerance received cyclopenthiazide $0.5 \mathrm{mg}$ daily.

Five patients received the potassium sparing treatment first followed by the potassium losing treatment. In the remainder the order was reversed. When results were examined for an effect of treatment order none was found. Apart from sublingual nitrate for control of angina, no other drugs were used during the study. Nitrates were avoided for at least two hours before the blood pressure recording or any of the cardiac investigations described below.

Each eight week treatment phase ended with a 24 hour stay in hospital, during which a strict metabolic diet containing $180 \mathrm{mmol}$ sodium and $60 \mathrm{mmol}$ potas-

Table 1 Patient characteristics sium was taken. Hormone, biochemical, and cardiac studies were carried out during these two inpatient periods as described below.

\section{CARDIAC INVESTIGATIONS}

Blood pressure was recorded by means of an automated version of the London School of Hygiene sphygmomanometer ${ }^{17}$ with patients supine at 1000 after a five minute period of rest and again after they had stood for two minutes. The diastolic blood pressure was taken as phase 5 of the Korotkoff sounds. One observer made all the recordings.

Ambulatory electrocardiograms were recorded on an Oxford Instruments Medilog two channel recorder for 24 hours. The recorded tape was played back on to paper by means of the American Edwards Co Eliminator playback unit. A complete disclosure of the entire tape was read manually by two independent observers, both of whom were unaware of the identity of each tape. Tapes were analysed for frequency of ventricular extrasystoles per hour and for grading on the Lown scale. ${ }^{18}$ Paired observations on the frequency of extrasystoles accorded to within $1 \%$ and there was complete agreement on Lown grades.

Exercise testing-A multistage treadmill stress test was performed during each hospital admission (Bruce protocol). End points for testing were ST depression on the electrocardiogram, the development of symptoms, or a heart rate greater than $90 \%$ of the predicted maximum.

Electrophysiological testing-The monophasic action potential was obtained by a close suction electrode (ABO Co, Tully, Sweden) positioned in the apex of the right ventricle and recorded on photographic paper at $100 \mathrm{~mm} / \mathrm{s}$ simultaneously with a surface electrocardiogram. Ten consecutive action potentials were manually digitised by means of a Wang desk top computer. The maximum height of each action potential was standardised to $100 \%$, and the action potential duration was measured at each $10 \%$ interval of amplitude. The relative slope of the upstroke was taken as the $90-10 \%$ upstroke time. The frequency response of

\begin{tabular}{|c|c|c|c|c|}
\hline Case No & Age (yr) & Sex & Ejection fraction ${ }^{\star}(\%)$ & Myocardial score $\dagger$ \\
\hline $\begin{array}{l}1 \\
2 \\
3 \\
4 \\
5 \\
6 \\
7 \\
8 \\
9 \\
10 \\
11 \\
\text { Mean (SEM) }\end{array}$ & $\begin{array}{l}63 \\
48 \\
55 \\
60 \\
56 \\
60 \\
63 \\
51 \\
57 \\
52 \\
58 \\
56(1 \cdot 4)\end{array}$ & $\begin{array}{l}\mathbf{M} \\
\mathbf{M} \\
\mathbf{M} \\
\mathbf{F} \\
\mathbf{M} \\
\mathbf{F} \\
\mathbf{M} \\
\mathbf{F} \\
\mathbf{M} \\
\mathbf{M} \\
\mathbf{M}\end{array}$ & $\begin{array}{l}49 \\
64 \\
40 \\
82 \\
79 \\
73 \\
70 \\
56 \\
62 \\
60 \\
71 \\
64(3 \cdot 8)\end{array}$ & $\begin{array}{c}7.4 \\
8.0 \\
5.4 \\
10.6 \\
10.2 \\
0.0 \\
9.6 \\
7.6 \\
2.0 \\
6.4 \\
6.4 \\
6.9(1.0)\end{array}$ \\
\hline
\end{tabular}

* Measured during left ventricular angiography.

$\dagger$ Scored according to the method of Brandt et al..$^{25}$ 
the system was DC $800 \mathrm{~Hz}$. We estimated the effective refractory period of the right ventricle and attempted induction of ventricular tachycardia with programmed extrastimuli. A bipolar pacing electrode was positioned in the apex of the right ventricle and up to three extrastimuli were applied after a train of eight paced beats for tachycardia induction. The effective refractory period was determined with a precision of $2 \mathrm{~ms}$. The protocol was based on a previously published method ${ }^{19}$ in which a maximum of three extrastimuli, but no rapid ventricular pacing, was used. The degree of myocardial electrical instability was assessed in two ways: firstly by a modification of a previously described system that takes into account both the number of repetitive responses as well as the number of stimuli required to produce the responses ${ }^{20}$; and, secondly, by the induction of a nonsustained ventricular tachycardia of at least three beats at a rate exceeding 100 beats/minute. Tachycardia induction was regarded as positive when the arrhythmia could be initiated in this way on three separate occasions.

Hormonal and biochemical measurements were undertaken on venous blood drawn at 0800 after an overnight fast and 12 hours of recumbency, and were repeated after 60 minutes of upright posture. Plasma aldosterone, ${ }^{21}$ adrenaline and noradrenaline, ${ }^{22}$ and angiotensin II concentrations, ${ }^{23}$ and plasma renin activity ${ }^{24}$ were measured by standard techniques. Venous blood was also taken in the fasting state $(0800)$ for measurement of plasma electrolyte concentrations. An arterial sample was drawn at the same time for blood gas and acid base determinations.

Coronary angiography was undertaken within three months of the study to assess the degree of coronary artery disease. A decrease of $>50 \%$ in lumen diameter was taken to indicate significant stenosis. The coronary angiograms were scored by the method of Brandt et al. ${ }^{25}$ This system allocates a numerical weighting to various portions of the left ventricle depending on the extent of the vascular supply. The degree of narrowing of each vessel supplying the left ventricle is then graded and a score out of a maximum of 15 units calculated. This score provides a measure of the extent of myocardium affected by the coronary disease. Ejection fraction was calculated by digital callipers according to a previously described method. ${ }^{26}$

\section{Results}

All but one patient completed the study without incident. The one exception was patient 11 (Table 1), who developed sustained ventricular tachycardia requiring DC shock during the electrophysiological study while in the potassium losing phase. He declined reinvestigation. Of the 11 patients, seven had abnormalities on the resting electrocardiogram recorded before the study. One showed voltage criteria for left ventricular hypertrophy, another had left anterior fascicular block, and in five there were non-specific $\mathrm{T}$ wave abnormalities.

Coronary angiography-Individual myocardial scores are given in Table 1. Five patients had single vessel disease, two had two vessel disease, and two had three vessel disease. One patient had only minor irregularities on the anterior descending coronary artery.

Blood pressure after diuretic treatment was not significantly different in the two groups. Mean lying pressure (mm Hg (SEM)) was $143(5 \cdot 2)$ systolic and $86(2 \cdot 3)$ diastolic after potassium sparing diuretics, and $135(3.4)$ systolic and $87(2.4)$ diastolic after potassium losing diuretics. Mean standing pressure was 135(4.9) systolic and $87(3.5)$ diastolic after potassium sparing diuretics, and $128(3.2)$ systolic and $81(3.8)$ diastolic after potassium losing diuretics.

Plasma electrolyte concentrations and biochemical indices (mean (SEM)) are given in Table 2. Plasma potassium concentration measured just before the study was $4 \cdot 15(0 \cdot 10) \mathrm{mmol} / \mathrm{l}$. The plasma potassium

Table 2 Plasma biochemical indices (mean (SEM))

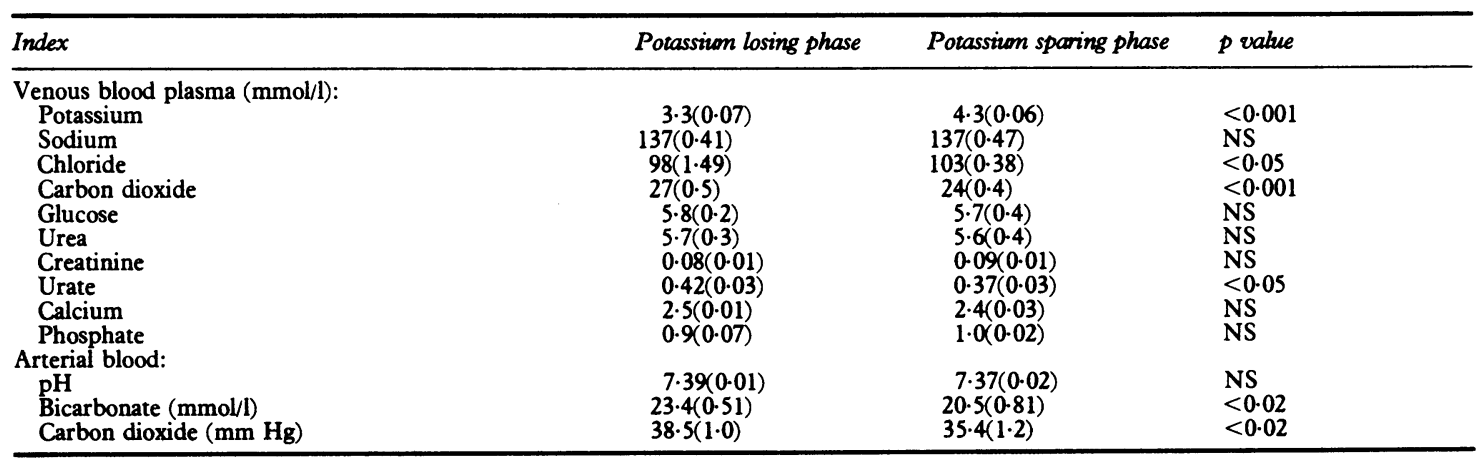

NS, not significant. 

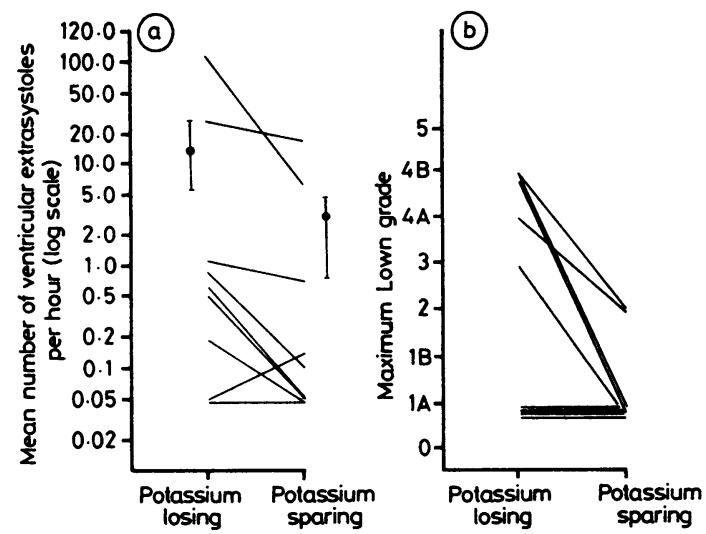

Fig. 1 (a) Mean number of ventricular extrasystoles per hour recorded over 24 hours in nine patients during ambulatory monitoring while taking potassitom losing and potassium sparing diuretics. Results are shown for individual patients and as mean (SEM). (b) Maximum Lown grade ventricular extrasystoles recorded during 24 hour ambulatory monitoring.

concentration was significantly lower (3.3(0.07) $\mathrm{mmol} / \mathrm{l})$ at the end of the potassium losing phase than at the end of the potassium sparing phase (plasma potassium $4.3(0.06) \mathrm{mmol} / \mathrm{l}(\mathrm{p}<0.001)$. Total venous carbon dioxide and arterial bicarbonate values were significantly higher during the potassium losing phase. There was no significant difference between treatment phases in plasma sodium, glucose, creatinine, urea, calcium, magnesium, and phosphate concentrations, but plasma chloride was lower $(\mathrm{p}<0.05)$ and plasma urate was higher $(\mathrm{p}<0.05)$ during the potassium losing phase than during the potassium sparing phase (Table 2).

Ambulatory electrocardiography-Because of a tape failure in one study, paired data were obtained in only nine patients. There was a significantly greater $(p<0.05)$ hourly frequency of ventricular extrasystoles and a higher Lown grade $(p<0.05)$ during the potassium losing phase than during the potassium sparing phase (Fig. 1). In seven of nine studies, the frequency of ventricular extrasystoles was greater during the potassium losing phase (Fig. 1). The Lown grade was higher in five patients during the potassium losing phase, but in the remaining four cases it was similar during both treatments (Fig. 1). There was no apparent relation between the frequency of ventricular extrasystoles or Lown grading and plasma potassium concentration.

Exercise testing-Exercise tests were positive in five patients, two on the basis of $1 \mathrm{~mm}$ horizontal ST segment depression, and angina developed in three. The mean duration of exercise was not significantly different in the two intervention phases $(470 \mathrm{~s}$ vs $435 \mathrm{~s}$ for the potassium losing and sparing phases respectively). Only two patients had ventricular

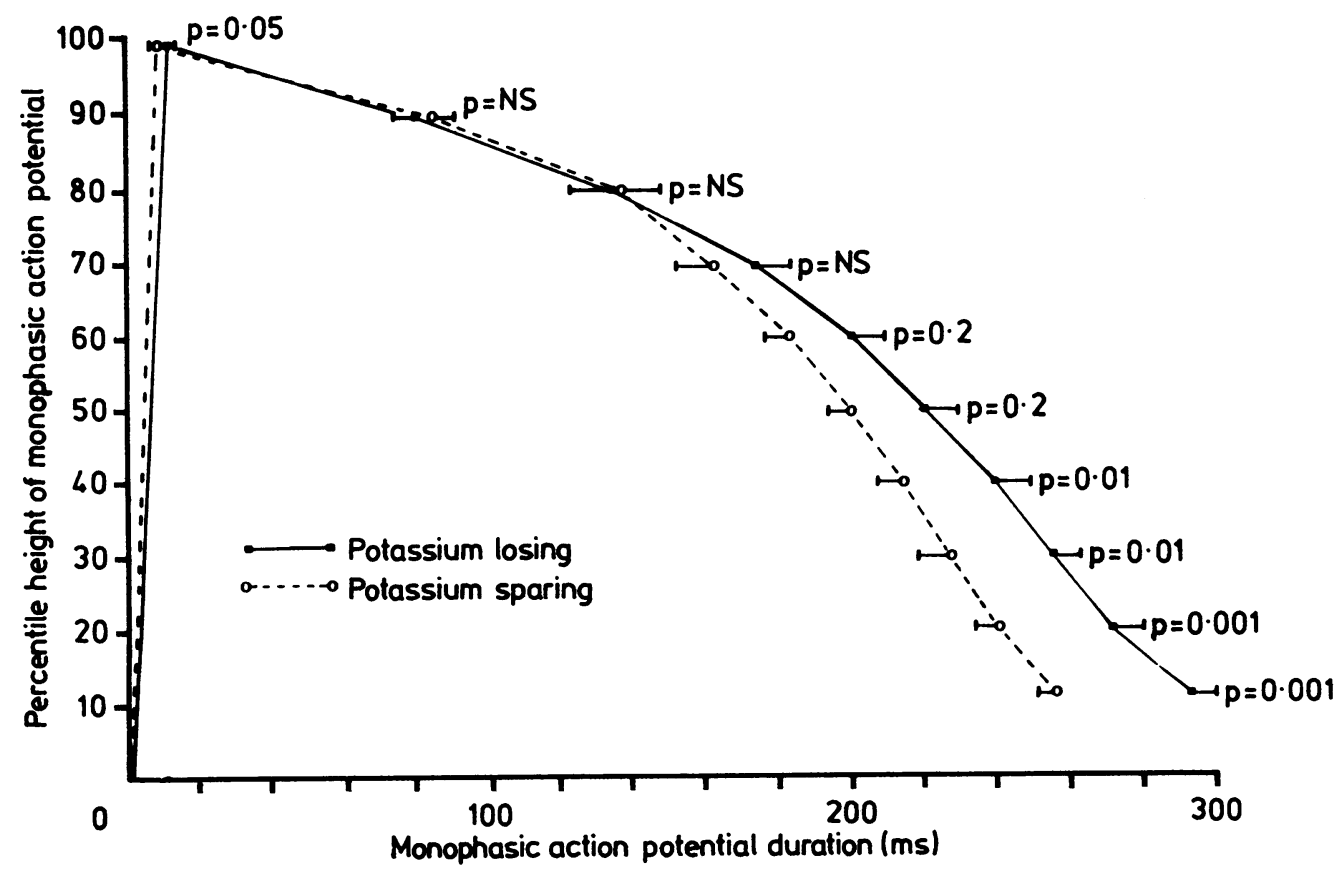

Fig. 2 Group mean time course of the monophasic action potential during potassizon losing and potassium sparing treatment. $p$ values were calculated by the paired $t$ test. 
extrasystoles during the exercise test. In both cases the ventricular extrasystoles occurred in the potassium losing phase and the same patients did not show any ventricular extrasystoles while taking the potassium sparing agents.

\section{ELECTROPHYSIOLOGICAL STUDIES}

Right ventricular monophasic action potential-The slope of the action potential upstroke was significantly $(p<0.05)$ steeper during the potassium sparing phase. Action potential duration at $50 \%$ repolarisation was prolonged during the potassium losing phase but this difference was not statistically significant. Action potential duration at $90 \%$ repolarisation, however, was significantly prolonged by hypokalaemia $(\mathrm{p}<0.001)$ (Fig. 2).

Right ventricular effective refractory period-The effective refractory period of the right ventricle during the potassium losing phase was significantly prolonged $(240(22) \mathrm{ms}$ ) compared with that during the potassium sparing phase $(216(10.8) \mathrm{ms}),(\mathrm{p}<0.05)$. The QT interval corrected for heart rate $(0.45(0.03) \mathrm{s}$

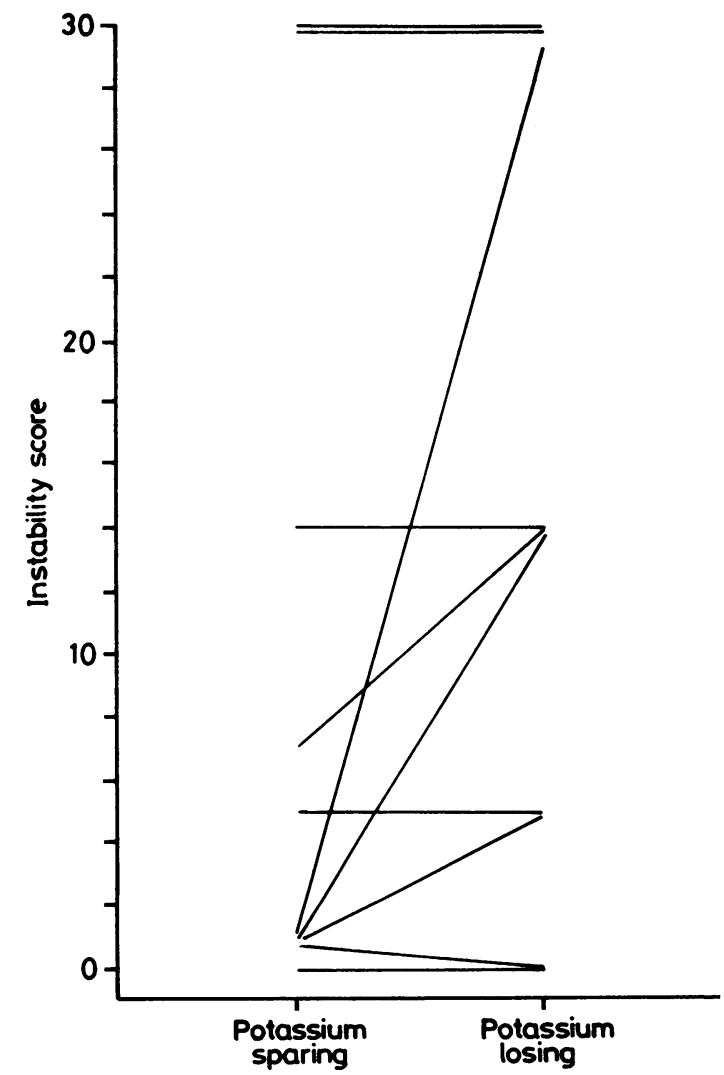

Fig. 3 Myocardial electrical instability score during potassium sparing and potassivm losing treament (see text for details of the scoring system). vs $0.44(0.02) \mathrm{s}$ ) showed a $2 \%$ prolongation in the potassium losing phase, but this change did not reach statistical significance.

Tachycardia induction studies-One patient developed sustained ventricular tachycardia requiring DC shock during the potassium losing phase. Because he refused to continue in the study he did not complete the potassium sparing phase. Data from the 10 paired studies are shown in Fig. 3. Four patients developed tachycardia and had higher myocardial electrical instability scores during the potassium losing phase than during potassium sparing phase. In all but one of the remaining patients the scores were the same with both treatment regimens. In one patient the score during the potassium sparing phase was slightly higher than that during the potassium losing phase. Nonsustained ventricular tachycardia was induced in five patients during the potassium losing phase and in three patients during the potassium sparing treatment phase.

Heart rate-Heart rate (mean (SEM)) in the potassium losing phase was $80.0(11.9)$ beats/min and 79.9
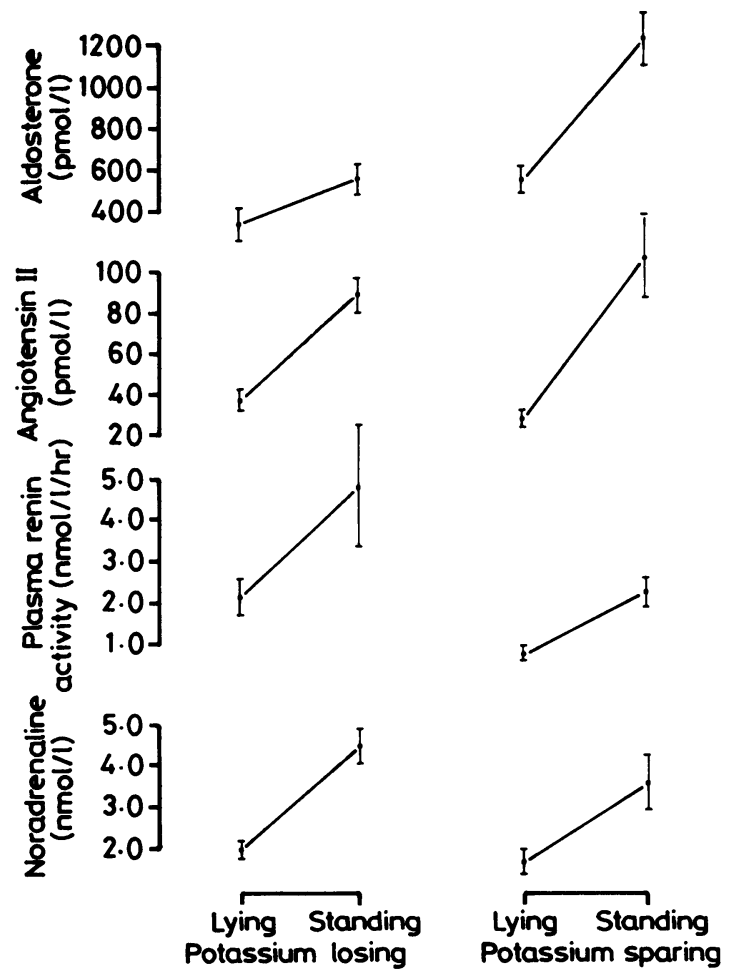

Fig. 4 Plasma concentrations of aldosterone, angiotensin $I I$, renin activity, and noradrenaline measured when patients were lying down or standing up while on potassium sparing and potassium losing therapy. Values are mean (SEM). Plasma aldosterone (both lying and standing values) was significantly higher $(p<0.001)$ duaing potassizon sparing treatment. 
$(11.0)$ beats/min during the potassium sparing phase.

\section{HORMONE RESULTS}

Hormone values when patients were lying or standing are shown in Fig. 4. Concentrations in supine patients and the rise in plasma noradrenaline and angiotensin II concentrations with erect posture were comparable in the two treatment phases. Plasma aldosterone, however, was significantly higher during treatment with potassium sparing diuretics $(p<0.001)$. Although plasma renin activity was lower in this phase, the difference was not statistically significant.

\section{Discussion}

Although severe potassium deficiency may precipitate life threatening cardiac arrhythmias, the effect of less severe hypokalaemia, particularly in patients with ischaemic heart disease, is controversial. ${ }^{11}{ }^{14}$ Recent studies have increased concern that conventional potassium losing diuretic treatment may be arrhythmogenic. The Medical Research Council mild hypertension study showed a significantly greater frequency of ventricular extrasystoles in patients treated with thiazide diuretics than in untreated control patients. ${ }^{27}$ Others have shown similar changes during thiazide treatment that were partly abolished by potassium repletion. ${ }^{1112}$ Observations of an increased incidence of ventricular fibrillation after acute myocardial infarction in hypokalaemic patients 2829 and of increased incidence of sudden death associated with high dose diuretic treatment of patients with mild hypertension 51516 add further to the concern. Although there were several explanations for these findings, the possibility of a causal relation between diuretic treatment and increased mortality in certain subgroups of hypertensive patients requires urgent clarification. There are, however, practical problems. To show a causal relation between hypokalaemia and sudden death in a small subgroup of patients requires a very large scale trial. ${ }^{14}$ In the absence of this information, the case for preventing diuretic induced hypokalaemia must be based on appropriately designed and controlled electrical trials showing a consistent association of increased myocardial electrical instability with potassium losing treatment.

We have examined prospectively in a randomised crossover controlled trial the effect of two short term diuretic treatments (one associated with potassium sparing and the other associated with potassium loss) in patients with mild essential hypertension and ischaemic heart disease. The hypotensive effect, and the degree of volume depletion as judged by body weight, activity of the renin angiotensin system, and catecholamine concentrations were comparable with the two treatments. There were significant differences between the two treatments in plasma potassium, acid base, chloride and urate concentrations that accorded with the known actions of the diuretics. Plasma aldosterone was significantly higher in the potassium sparing phase as previously reported.$^{30}$ More importantly, consistent electrophysiological changes occurred in all patients during the potassium losing phase, and there was evidence of increased cardiac electrical instability as measured by several different standardised techniques. While animal and in vitro studies have shown that severe hypokalaemia (plasma potassium $<3.0$ $\mathrm{mmol} / \mathrm{l}$ ) is associated with increased membrane potential negativity, increased rate of depolarisation, and increased duration of action potential ${ }^{31}{ }^{32}$ the present study is the first to show that similar changes in action potential occur in man during modest changes in plasma potassium. Prolongation of action potential duration is indicative of delayed repolarisation. There was no significant difference between the two treatment phases at $50 \%$ repolarisation. This measurement includes phase 0,1 , and 2 of the action potential. Significant prolongation of the action potential was evident at $90 \%$ repolarisation during the potassium losing phase but not at $50 \%$. This suggests that delayed repolarisation due to moderate hypokalaemia is mainly attributable to prolongation of phase 3 of the action potential. The action potential duration is heart rate dependent but rates during both treatment phases were identical; thus heart rate was not a factor responsible for the difference in delayed repolarisation in the potassium losing phase. Delayed repolarisation is usually estimated from the QT interval of the surface electrocardiogram. This is a measurement which is imprecise since it is often difficult to define the start and end of the QT segment in the surface electrocardiogram. There is no universal agreement on the choice of lead from which this measurement is to be made. In contrast to this the monophasic action potential can define the phases of excitation and repolarisation with a high degree of precision. ${ }^{33}$ These factors probably explain why we found more consistent and significant changes in the potassium losing phase from analysis of the monophasic action potential than from the QT segment measurement. A generalised electrophysiological effect of the potassium losing treatment is supported by lengthening of the effective refractory period of the right ventricle in every patient.

If delayed repolarisation is homogeneous it may exert an antiarrhythmic effect. Heterogeneous repolarisation, however, has been shown to be associated with an increased risk of serious ventricular arrhythmias in congenital syndromes, ${ }^{34}$ after myocardial infarction, ${ }^{35}$ and after certain drugs. ${ }^{36}$ To evaluate this effect further, we examined measures of cardiac electrical instability in patients at rest and during 
exercise as well as during programmed intracardiac stimulation. From 24 hour recordings we found a significantly increased frequency of ventricular extrasystoles and a significantly higher Lown grading in the potassium losing phase-findings which are consistent with previous reports. ${ }^{1127}$ Exercise induced ventricular extrasystoles occurred in only two of 20 studies and both patients were taking a potassium losing diuretic. This low frequency of ventricular extrasystoles during exercise (compared with that seen during ambulatory monitoring) is similar to previous reports. ${ }^{11}$

Although these results are consistent with increases in cardiac electrical instability associated with the potassium losing treatment, it is doubtful whether such findings alone constitute proof of increased susceptibility to life threatening arrhythmias. ${ }^{37} 38 \mathrm{We}$ therefore sought additional information by inducing tachycardia by programmed intracardiac stimulation-a technique which is regarded as a reliable predictor of serious arrhythmias..$^{39-41}$ The electrical stability of the myocardium was assessed in two ways. Firstly, the frequency of induced ventricular tachycardia was measured, and secondly, we used a scoring system that takes into account both the number of repetitive responses as well as the number of stimuli required. Non-sustained ventricular tachycardia developed in five patients during the potassium losing phase and in three patients during the potassium sparing phase. In most patients the electrical instability score was similar for both diuretic treatments; thus overall there was no statistical difference between scores from the two phases of treatment. In those patients in whom there was a change (increase or decrease in score) electrical instability increased in four and decreased slightly in only one patient during the potassium losing phase of treatment.

While our observations of increased myocardial electrical instability may be explicable on the basis of potassium depletion, other factors could be involved. In keeping with previous reports ${ }^{11}$ we found no correlation between plasma potassium concentration and indices of cardiac electrical instability. Despite the suggested importance of magnesium ${ }^{42}$ there were no significant differences in plasma magnesium between the two treatment phases. The possibility of diuretic induced hormonal changes, particularly in noradrenaline, contributing to increased electrical instability was investigated, with negative results. Further research is needed to evaluate the contribution of factors other than potassium.

As recently emphasised, no single technique is yet available to identify patients at high risk of sudden cardiac death. ${ }^{43}$ Our study has examined myocardial electrical function in several ways and is not depen- dent on a single technique for its conclusions. The results show that diuretic induced changes in plasma potassium are associated with demonstrable electrophysiological changes in all patients, that most showed increased frequency and complexity of ventricular extrasystoles, and that some had exercise induced arrhythmias. A smaller number were more susceptible to ventricular arrhythmias elicited by intracardiac stimulation. These findings, obtained in a small number of carefully studied patients, seem to reflect the clinical situation in which most patients may well have electrophysiological changes, but only a small proportion have major or fatal arrhythmias. It should be noted that our patients were not a high risk group; none had extensive coronary artery disease, history of significant arrhythmia, cardiac failure, or use of digitalis or other cardioexcitatory drugs. Since it is easier to prevent potassium deficiency than to treat it, ${ }^{44}$ we conclude that a reduction in plasma potassium should be avoided in patients with ischaemic heart disease requiring diuretics.

We thank the Medical Research Council of New Zealand for financial support. Part of this study was undertaken when DES was in receipt of a grant from the Canterbury Medical Research Foundation.

\section{References}

1 Davidson S, Surawicz B. Ectopic beats and atrioventricular conduction disturbances in patients with hypopotassaemia. Arch Intern Med 1967; 120: 280-5.

2 Kunin AS, Surawicz B, Sims EAH. Decrease in serum potassium concentrations and appearance of cardiac arrhythmias during infusion of potassium with glucose in potassium-depleted patients. $N$ Engl $\mathcal{F}$ Med 1962; 266: 228-33.

3 Pedersen DH, Zipes DP, Foster PR, Troup PJ. Ventricular tachycardia and ventricular fibrillation in a young population. Circulation 1979; 60: 988-97.

4 Surawicz B, Lepeschkin E. The electrocardiographic pattern of hypopotassemia with and without hypocalcemia. Circulation 1953; 8: 801-27.

5 Nordrehaug JE. Malignant arrhythmias in relation to serum potassium values in patients with an acute myocardial infarction. Acta Med Scand [Suppl] 1981; 647: 101-7.

6 Lown B, Weller JM, Wyatt N, Hoigne R, Merrill JP. Effect of alterations of body potassium on digitalis toxicity [Abstract]. F Clin Invest 1952; 31: 648.

7 Duke M. Thiazide-induced hypokalemia. Association with acute myocardial infarction and ventricular fibrillation. FAMA 1978; 239: 43-5.

8 Altmann P, Hamblin JJ. Ventricular fibrillation induced by xipamide. $\operatorname{Br}$ Med $\mathcal{F}$ 1982; 284: 494.

9 Bigger JR Jr, Weld FM. Drugs and sudden cardiac death. Ann NY Acad Sci 1982; 382: 229-37.

10 Cembrowski GS, Huntington RW, 3rd. Probable fatal cardiac dysrhythmia secondary to diuretic-induced 
hypokalaemia. Am $\mathcal{F}$ Forensic Med Pathol 1981; 2: 243-8.

11 Holland OB, Nixon JV, Kuhnert L. Diuretic-induced ventricular ectopic activity. Am F Med 1981; 70: 762-8.

12 Caralis PV, Materson BJ, Perez-Stable E. Potassium and diuretic-induced ventricular arrhythmias in ambulatory hypertensive patients. Miner Electrolyte Metab 1984; 10: 148-54.

13 Gifford RW Jr. A guide to the practical use of diuretics. FAMA 1976; 235: 1890-3.

14 Harrington JT, Isner JM, Kassirer JP. Our national obsession with potassium. Am F Med 1982; 73: 155-9.

15 Multiple Risk Factor Intervention Trial Research Group. Multiple risk factor intervention trial. FAMA 1982; 248: 1465-77.

16 Holme I, Helgeland A, Hjermann I, Leren P, LundLarsen PG. Treatment of mild hypertension with diuretics. FAMA 1984; 251: 1298-9.

17 Rose GA, Hollan WW, Crowley EA. A sphygmomanometer for epidemiologists. Lancet 1964; i: 296300.

18 Lown B, Wolf $M$. Approaches to sudden death from coronary heart disease. Circulation 1971; 44: 130-42.

19 Horowitz LN, Josephson ME, Farshidi A, Speilman SR, Michelson EL, Greenspan AM. Recurrent sustained ventricular tachycardia. 3. Role of the electrophysiologic study in selection of antiarrhythmic regimens. Circulation 1978; 58: 986-97.

20 Jones-Collins BA, Patterson RE. Quantitative measurement of electrical instability as a function of myocardial infarct size in the dog. Am F Cardiol 1981; 48: 858-63.

21 Lun S, Espiner EA, Nicholls MG, Yandle TG. A direct radioimmunoassay for aldosterone in plasma. Clin Chem 1983; 29: 268-71.

22 Peuler JD, Johnson GA. Simultaneous single isotope radio-enzymatic assay of plasma norepinephrine, epinephrine and dopamine. Life Sci 1977; 21: 625-36.

23 Nicholls MG, Espiner EA. A sensitive, rapid radioimmunosassay for angiotensin II. $N Z$ Med $f$ 1976; 83: 399-403.

24 Dunn PJ, Espiner EA. Outpatient screening tests for primary aldosteronism. Aust NZ F Med 1976; 6: 131-5.

25 Brandt PWT, Partridge JB, Wattie WJ. Coronary arteriography: method of presentation of the arteriogram report and a scoring system. Clin Radiol 1977; 28: 361-5.

26 Bones PJ, Ikram H. A method of left ventricular ejection fraction estimation from cineangiocardiograms employing a special-purpose calculator. Cardiovasc Res 1977; 11: 470-4.

27 Medical Research Council Working Party on Mild to Moderate Hypertension. Ventricular extrasystoles during thiazide treatment: sub-study of MRC mild hypertension trial. Br Med F 1983; 287: 1249-53.

28 Solomon RJ, Cole AG. Importance of potassium in patients with acute myocardial infarction. Acta Med
Scand [Suppl] 1981; 647: 87-93.

29 Nordrehaug JE, von der Lippe G. Hypokalaemia and ventricular fibrillation in acute myocardial infarction. $\mathrm{Br}$ Heart $f$ 1983; 50: 525-9.

30 Nicholls MG, Espiner EA, Hughes H, Rogers T. Effect of potassium-sparing diuretics on the renin-angiotensinaldosterone system and potassium retention in heart failure. Br Heart f 1976; 38: 1025-30.

31 Hoffman BF, Cranefield PF. Electro-physiology of the heart. New York: McGraw-Hill, 1960.

32 Fisch C, Knoebel SB, Feigenbaum H, Greenspan K. Potassium and the monophasic action potential, electrocardiogram, conduction and arrhythmias. Prog Cardiovasc Dis 1966; 8: 387-418.

33 Edvardsson N, Hirsch I, Olsson SB. Right ventricular monophasic action potentials in healthy young men. PACE 1984; 7: 813-21.

34 Schwartz PJ, Periti M, Malliani A. The long Q-T syndrome. Am Heart f 1975; 89: 378-90.

35 Schwartz PJ, Wolf S. QT interval prolongation as predictor of sudden death in patients with myocardial infarction. Circulation 1978; 57: 1074-7.

36 Reynolds EW, Vander Ark CR. Quinidine syncope and the delayed repolarisation syndromes. Mod Concepts Cardiouasc Dis 1976; 45: 117-22.

37 Morganroth J, Michelson EL, Horowitz LN, Josephson ME, Pearlman AS, Dunkman WB. Limitations of routine long-term electrocardiographic monitoring to assess ventricular ectopic frequency. Circulation 1978; 58: 408-14.

38 Michelson EL, Morganroth J. Spontaneous variability of complex ventricular arrhythmias detected by long-term electrocardiographic recording. Circulation 1980; 61: 690-5.

39 Greene HL, Reid PR, Schaeffer AH. The repetitive ventricular response in man: a predictor of sudden death. $N$ Engl f Med 1978; 299: 729-34.

40 Ruskin JN, DiMarco JP, Garan H. Out-of-hospial cardiac arrest: electrophysiologic observations and selection of long-term antiarrhythmic therapy. $N$ Engl $\mathcal{F} \mathrm{Med}$ 1980; 303: 607-13.

41 Ruskin JN, Schoenfeld MH, Garan H. Role of electrophysiologic techniques in the selection of antiarrhythmic drug regimens for ventricular arrhythmias. $\mathrm{Am}$ f Cardiol 1983; 52: 41c-6c.

42 Dyckner T, Wester PO. Ventricular extrasystoles and intracellular electrolytes before and after potassium and magnesium infusions in patients on diuretic treatment. Am Heart $\mathcal{F}$ 1979; 97: 12-8.

43 Lesch M, Kehoe RF. Predictability of sudden cardiac death. N Engl f Med 1984; 310: 255-7.

44 Morgan T, Myers J. Potassium maintenance. Potassium supplements or potassium sparing agents. Acta Med Scand [Suppl] 1981; 647: 117-23. 